\title{
Atrioventricular and sinoatrial block in thyrotoxic crisis
}

\author{
M R KRAMER, S SHILO, C HERSHKO \\ From the Department of Medicine, Shaare Zedek Medical Centre, ferusalem, Israel
}

SUMMARY A 55 year old woman in thyrotoxic crisis developed atrial fibrillation, atrioventricular block, and sinoatrial block in rapid succession. All of these abnormalities resolved completely after antithyroid treatment. This course of events illustrates the profound effect of thyroid hormones on cardiac function. In view of the potential aggravation of atrioventricular conduction disturbance by beta adrenergic blocking agents, thyrotoxic patients should be carefully screened for electrocardiographic evidence of conduction disturbance before the administration of such drugs.

Hyperthyroidism is commonly associated with sinus tachycardia and atrial fibrillation. A less well known complication of thyrotoxicosis is impaired atrioventricular conduction. Complete atrioventricular block complicating hyperthyroidism has generally been described in patients with additional risk factors such as infection, drugs, or electrolyte imbalance. ${ }^{1-6}$ In a few, however, thyrotoxicosis was the only cause of atrioventricular block. ${ }^{45} \mathrm{We}$ describe a patient with thyrotoxic crisis in whom atrial fibrillation, atrioventricular block, and sinoatrial block developed in rapid succession. All of these abnormalities resolved after antithyroid therapy.

\section{Case report}

A 55 year old Arab woman was admitted to this hospital in August 1983 because of progressive weakness, dyspnoea, diarrhoea, and a weight loss of about $10 \mathrm{~kg}$ in recent months. Hyperthyroidism had been diagnosed two years before and she had been treated with propylthiouracil and digoxin, but these drugs had been stopped a month before admission.

On examination she was pale, tense, and moderately dyspnoeic. Blood pressure was $170 / 70 \mathrm{~mm}$

Requests for reprints to Professor C Hershko, Department of Medicine, Shaare Zedek Medical Centre, PO Box 293, Jerusalem, Israel.
$\mathrm{Hg}$ and her pulse was regular ( 100 beats/min). There was bilateral lid lag and impaired convergence. The thyroid gland was diffusely enlarged with an audible bruit. Her skin was warm and moist, and she had a fine tremor of the hands. There was a loud first heart sound and a $3 / 6$ systolic murmur over the heart apex and the pulmonary area.

Laboratory examinations showed a haemoglobin concentration of $9.5 \mathrm{~g} / \mathrm{dl}$, white blood cell count of $4900 / \mathrm{mm}^{3}$, and sedimentation rate of $36 \mathrm{~mm} / \mathrm{h}$. Triiodothyronine resin uptake was $48 \%$ (normal $25-45$ ) and serum thyroxine concentration was $30 \mu \mathrm{g} / \mathrm{dl}$ (normal 4.5-11.5 $\mu \mathrm{g} / \mathrm{dl}$ ) $(386 \mathrm{nmol} / 1$, normal $58-148$ $\mathrm{nmol} / \mathrm{l})$. The concentration of serum thyroid stimulating hormone was $2.0 \mu \mathrm{U} / \mathrm{ml}$ (normal $10 \mu \mathrm{U} / \mathrm{ml}$ ). There were no antithyroid antibodies. Routine blood biochemical analysis including serum calcium was normal, apart from a serum alkaline phosphatase concentration of $170 \mathrm{IU} / 1$ (normal 40-80 IU/1). The electrocardiogram on admission was normal with a sinus rhythm of 100 beats per minute and a PR interval of $0.16 \mathrm{~s}$. An $x$ ray film of the chest showed moderate bilateral congestion of pulmonary vessels. An echocardiographic study showed asymmetric hypertrophy of the septum. She was started on daily doses of propylthiouracil $(600 \mathrm{mg})$ together with digoxin $(0.25 \mathrm{mg})$ and frusemide $(40 \mathrm{mg})$. One day later a transient episode of atrial fibrillation was recorded. 


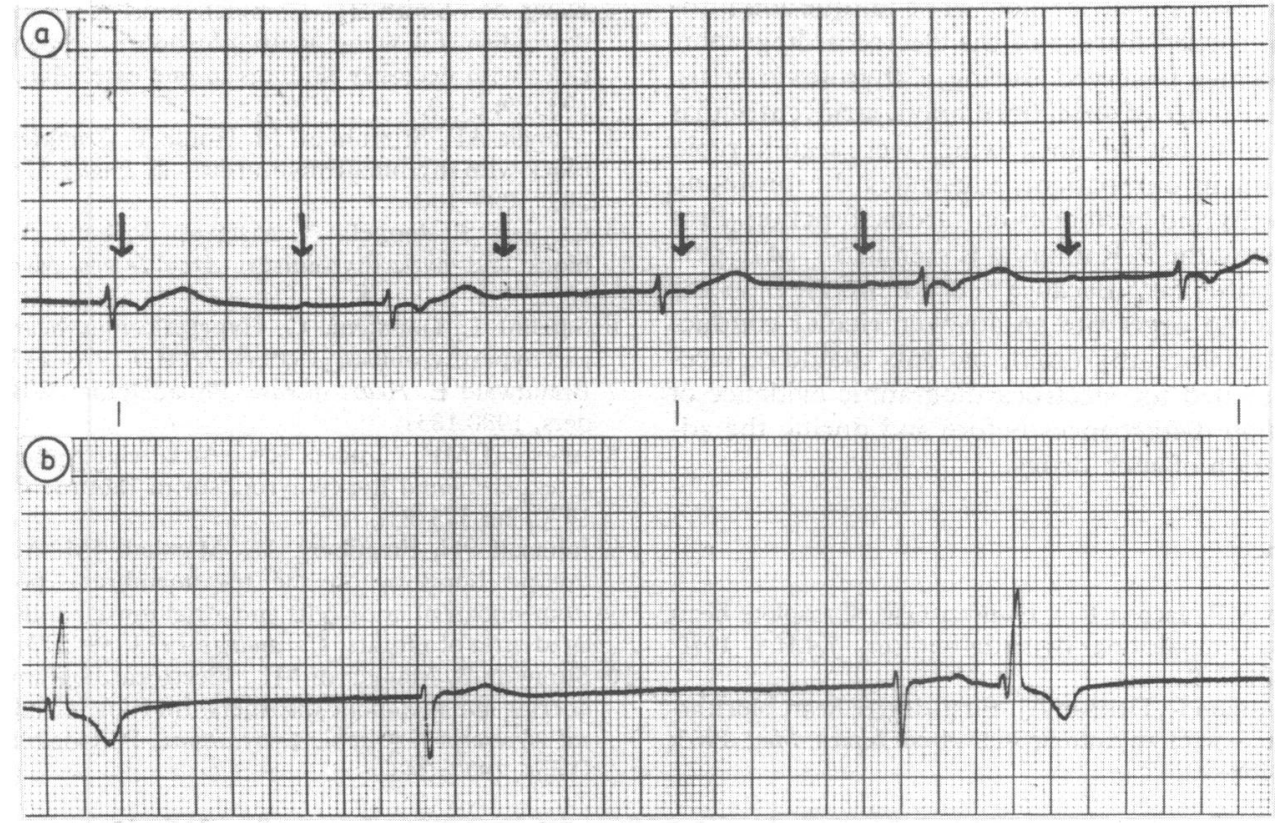

Figure Electrocardiograms in a patient in thyrotoxic crisis showing (a) complete atrioventricular dissociation (arrow's indicate $P$ waves) and (b) sinoatrial block with ventricular escape.

After three days in hospital the patient's diarrhoea increased and her temperature rose to $38^{\circ} \mathrm{C}$. On the same day, after a single oral dose of propranolol (10 $\mathrm{mg}$ ) there was an episode of syncope. A repeat electrocardiogram after syncope showed complete atrioventricular dissociation with an atrial rate of 66 beats per minute and ventricular rate of 23 beats per minute (Fig. a). After treatment with atropine and isoprenaline and withdrawal of propranolol, atrial fibrillation developed and this was followed by the resumption of sinus rhythm. Although sinus rhythm was largely maintained thereafter, several short episodes of sinoatrial block with ventricular escape were recorded (Fig. b). In the following days huge inverted $T$ waves appeared in the anterior chest leads without ischaemic chest pains and without raised concentrations of serum enzymes.

She continued to have a high temperature. All blood and stool cultures were negative. Severe left heart failure and stupor developed. The daily dose of propylthiouracil was increased to $1 \mathrm{~g}$ and a larger dose of diuretic was given. These measures were followed by gradual improvement with a return to normal body temperature and bowel movements. Three weeks after admission she was given $8 \mathrm{mCi}$ of iodine-131. Two months later her serum thyroxine had fallen to $14 \mu \mathrm{g}(180 \mathrm{nmol} / \mathrm{l})$, the triiodothyronine resin uptake was $30 \%$, and the electrocardiogram was normal. She is in good health 18 months later and requires no drug treatment.

\section{Discussion}

Although abnormal atrioventricular conduction has been reported in some patients with thyrotoxicosis, ${ }^{1-6}$ this abnormality is not generally acknowledged to be a complication of hyperthyroidism, which is more commonly associated with sinus tachycardia and atrial fibrillation. ${ }^{7-9}$ Complete heart block associated with thyrotoxicosis has generally been seen in patients with additional risk factors such as infectious diseases, ${ }^{3}$ rheumatic fever, ${ }^{1}$ hypercalcaemia, ${ }^{6}$ or digitalis treatment. In such patients, complete heart block might have been the result of a primary insult aggravated by the presence of thyrotoxicosis. In other patients, however, thyrotoxicosis has been the only underlying disease, and control of thyroid disease has restored normal atrioventricular conduction. ${ }^{45}$ In our patient no risk factor other than hyperthyroidism was identified and all cardiac problems were resolved after antithyroid therapy. It should be noted, however, that atrioventricular dissociation was first observed after a small $(10 \mathrm{mg})$ dose of propranolol and a possible role for this drug in precipitating the conduction disturbance cannot be excluded. 
Episodes of sinoatrial block are a unique and hitherto unrecorded feature of the electrocardiographic abnormalities observed during a thyrotoxic crisis. The coexistence of atrial fibrillation, atrioventricular block, and sinoatrial block, which were seen in rapid succession in our patient, illustrates the profound effect of thyroid hormones on cardiac function. Prolongation of the P-R interval is seen in 5\% of hyperthyroid patients. ${ }^{10}$ Because beta adrenergic blocking agents could aggravate an atrioventricular conduction disturbance, thyrotoxic patients should be carefully screened for electrocardiographic evidence of conduction disturbances before and during the administration of such drugs.

\section{References}

1 Stern MP, Jacobs RL, Duncan GW. Complete heart block complicating hyperthyroidism. $\mathcal{F} A M A$ 1970; 212: 2117-9.

2 Rosenblum R, Delman AJ. First-degree heart block associated with thyrotoxicosis. Arch Intern Med 1963; 112: 488-90.
3 Davis AC, Smith HL. Complete heart block in hyperthyroidism following acute infections: a report of six cases with necropsy findings in one case. Am Heart $\mathcal{f}$ 1933; 9: 81-9.

4 Muggia AL, Stjernholm M, Houle T. Complete heart block with thyrotoxic myocarditis. N Engl f Med 1970; 283: 1099-100.

5 Campus S, Rappelli A, Malavasi A, Satta A. Heart block and hyperthyroidism. Arch Intern Med 1975; 135: 1091-5.

6 Sataline L, Donaghue G. Hypercalcemia, heart-block and hyperthyroidism [Letter]. $\mathcal{F} A M A$ 1970; 213: 1342.

7 Braunwald E. Heart disease. Philadelphia: WB Saunders, 1980:1831.

8 Arnsdorf MF; Childers RW. Atrial electrophysiology in experimental hyperthyroidism in rabbits. Circ Res 1970; 26: 575-81.

9 Johnson PN, Freedberg AS, Marshall JM. Action of thyroid hormone on the transmembrane potentials from sinoatrial node cells and atrial muscle cells in isolated atria of rabbits. Cardiology 1973; 58: 273-89.

10 Surawitz B, Mangiardi ML. Electrocardiogram in endocrine and metabolic disorders. In: Rios JC, ed. Clinical electrocardiographic correlations. Philadelphia: FA Davis, 1977: 243. 